\title{
Simulation of Spatial Distribution of Rare Species in Protected Natural Areas (on the Example of the Central Forest Reserve, Russia)
}

\author{
Anatoly V. Istomin \\ Pskov State University, Pskov, Russia \\ Central Forest State Nature Biosphere \\ Reserve, \\ Russia, Tver region \\ email: C.gl@mail.ru
}

\begin{abstract}
An important task of modern ecology is the modeling of the spatial distribution of organisms. Of particular relevance is the modeling of the distribution of rare species in protected natural areas. The paper discusses the main stages and presents the results of modeling the habitat suitability of the Central Forest State Nature Biosphere Reserve (Russia, Tver region) for the red vole. This species is a rare and relict for the center of the CaspianBaltic watershed. In the modelling the maximum entropy method (MaxEnt) was used. The basis for building the model was the field sampling of the authors, performed in July-August 2010-2014. Each year, trapping were carried out at 745 sampling points each of which has geographical referencing in the WGS 84. A total of 12238 trap-days were worked out and 141 red vole individuals were caught. In the process of modeling, the contribution to the species distribution of certain integral characteristics of habitats (relief, vegetation type and three vegetation spectral indices) was determined. A map model of habitat suitability for the red vole on the territory of the Reserve was built, which allowed to describe the spatial structure of the population groups of the species. The total areas of the most favorable sites for the habitat of the red vole on the reserve's territory were calculated.
\end{abstract}

Keywords-modelling, maximum entropy habitat, GIS analysis, MaxEnt, rare species, protected natural areas, red vole.

\section{INTRODUCTION}

Important challenge of modern ecology is the modeling of the spatial distribution of organisms. To build good-quality models, it is necessary to take into account a large number of ecological factors and peculiarities of their influence on organisms. Simulation of the spatial distribution will have a probabilistic nature, since ecosystems are non-equilibrium thermodynamic systems, the parameters of which change $[1 ; 2 ; 3]$. Of particular relevance is the modeling of the spatial distribution of organisms due to climate change, the natural dynamics and the anthropogenic transformation of natural systems $[4 ; 5]$. These studies are important for research of the distribution of rare and invasive species, the historical

\author{
Sergey G. Mikhalap \\ Pskov State University, Pskov,Russia \\ email: sgmikhalap@gmail.com
}

aspects of the formation of biodiversity, the organization of environmental monitoring and conservation measures $[6 ; 7 ; 8]$.

The priority role in the conservation of biodiversity, including rare species, belongs to protected natural areas. The Central Forest State Nature Biosphere Reserve (Russia, Tver region) is very important in preserving biodiversity in the Caspian-Baltic watershed. Eastern Palaearctic species of small mammals belong to the relict species and are extremely rare for this region.

This paper discusses the main stages and presents the results of modeling the habitat suitability the core of the Central Forest Reserve for example of one of the relict species of rodents.

\section{MATERIALS AND METHODS}

The object of the study was the red vole (Myodes rutilus Pall.) is a typical species of the Eastern Palaearctic. The red vole currently has an extensive range. The species is spread in Fennoscandia, in the north of the European part of Russia, Siberia, the Far East, Kamchatka, and Sakhalin Island $[9 ; 10 ; 11]$. In the Central Forest Reserve, the species is located on the southwestern periphery of the range and is distributed sporadically [12].

The territory of the Reserve is a moraine plain of the Valdai glaciation with altitudes of $230-310 \mathrm{~m}$ above sea level. The region belongs to the southern taiga subzone. The soil cover is characterized by complexity and differentiation [13]. The vegetation cover is mainly represented by southern taiga spruce forests and secondary forests [14]. Boreal spruce forests are found on poorly dissected watersheds. Well-drained slopes of watersheds are occupied by nemoral spruce forests. Spruce forests nemoral-boreal are spread on weakly drained slopes.

In this work, the maximum entropy method to simulate the spatial distribution of the species was used $[3 ; 6]$, successfully implemented in the program MaxEnt 3.4.1. For the application of the method, only the presence of the species at a point of observation is sufficient. The result of the study is a spase model of habitat suitability with predicted probabilities of the presence of the species

This is an open access article under the Creative Commons Attribution 4.0 International License. 
in each cell of the raster map.

The basis for the construction of the model were the author's field materials, performed in July-August 20102014. Trapping of small mammals was carried out on a transect of $2280 \mathrm{~m}$ in length, which crossed various types of ecosystems of the reserve [15]. There are 114 central points on the transect, the distance between them is 20 meters. The points have detailed geobotanical descriptions on areas of $20 \times 20$ and $5 \times 5$ meters. Five traps were placed crosswise at each central point with a distance of 5 $\mathrm{m}$ from each other. In addition, data from seven standard counting traps lines (25 traps, $125 \mathrm{~m}$ ) were added. They located in various types of spruce forests of nemoral and boreal genesis. Thus, annually catches were carried out at 745 sampling points each of which has geographical referencing in the WGS 84 coordinate system. A total of 12238 trap-days were worked out and 141 red vole were caught.

Preparation and processing of raster data was carried out in the QGIS 3.4. Were used: a vegetation type classification file resulting from classification of the Sentinel-2 satellite image and integral habitat characteristics: relief and vegetation spectral indices (NDVI - Normalized DifferenceVegetation Index, reflecting the amount of photosynthetically active biomass; LAI - Leaf Area Index, characterizing the degree of leaf cover ; GRVI - Green-Red Vegetation Index, reflect the change of vegetation types). The vegetation indices were calculated using the raster calculator tool in QGIS. The quality of the classification of vegetation types was checked by the field descriptions of transects for the corresponding points.

The MaxEnt program requires that all environmental geodata have single geographic characteristics (coordinate system, pixel cell size, and extent). To solve the problem of heterogeneity of the source data (digital elevation model, classification file with the main types of vegetation, vegetation indices), a regular vector grid with a cell size of $20 \times 20 \mathrm{~m}$ over the whole study area was created. Further, all the initial data were converted to raster format, and then using the QGIS "zonal statistics" tool were recorded into the attribute table of the polygonal grid layer. On this basis, thematic roasters were created which were converted to the ASCII format and were loaded into Maxent along with the species presence points.

Verification of models quality were carried out on a test samples. For this purpose, $25 \%$ of the initial sample points of the red vole were used, randomly selected from the original sample. The obtained AUC values were evaluated on an expert scale [3].

\section{RESULT AND DISCUSSION}

The modelling shows that the best results are obtained by using the bootstrap method with 500 iterations, at which AUC values $=0.94$, and the standard deviation does not exceed 0.003 (Fig. 1). This quality of the model, according to the expert scale, is characterized as excellent.

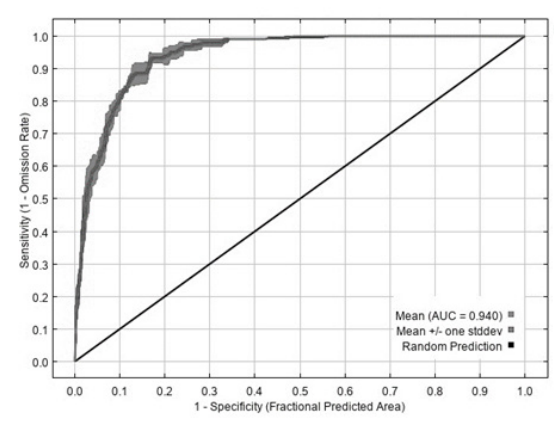

Fig. 1. ROC-curve for model of habitat suitability for M. rutilus

One of the tasks of spatial ecological modeling is the answer to the question of which environmental variables make the greatest contribution to the description of the spatial distribution of the species $[1,2]$. The average values of the contributions of the characteristics of the environment to the spatial distribution model of the red vole are showed in Table 1.

TABLE 1. CONTRIBUTION OF ENVIRONMENTAL
CHARACTERISTICS TO THE MODEL OF THE SPATIAL DISTRIBUTION OF THE RED VOLE

\begin{tabular}{|l|c|}
\hline \multicolumn{1}{|c|}{ Variable } & Percent contribution \\
\hline Relief & 55,0 \\
\hline Type of vegetation & 34,5 \\
\hline NDVI & 6,9 \\
\hline GRVI & 3,1 \\
\hline LAI & 0,4 \\
\hline
\end{tabular}

The relief is the first contributor to the space distribution of the red vole. The second most important factor is the type of vegetation. The impact of the NDVI index is noticeable, which serves as an indicator of the "productivity" of the habitat.

Taking into account all said environment parameters on the territory of the Central Forest Reserve, a cartographic model of habitat suitability for the red vole was constructed (Fig. 2). The model predicts the presence in the reserve of five relatively large areas with good habitat suitability for the red vole. Each of these areas has spots with a very high probability of presence of the species, which can be considered the "core" of population groups. A certain similarity in the configuration of the areas attracts attention. They have a continuous tape character, which can provide the specifics of the most likely movement of individuals throughout the Reserve area.

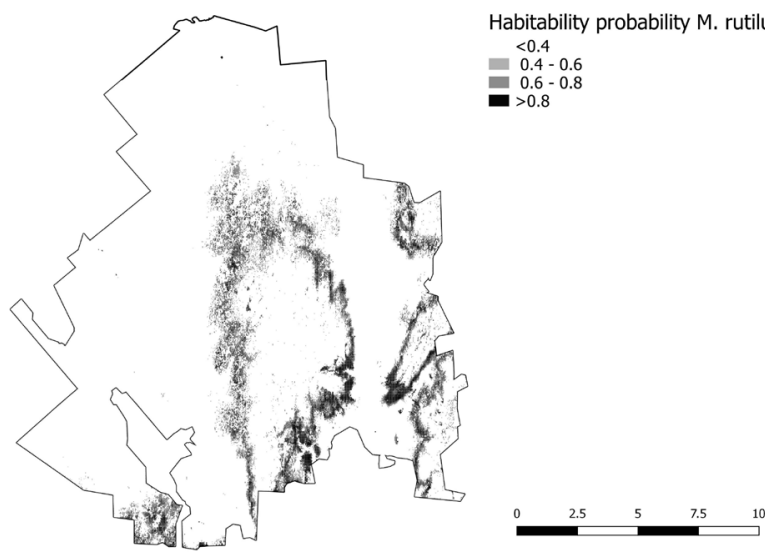

Fig. 2. Map model of habitat suitability for the red vole in the Central Forest Biosphere Reserve 
On the basis of the constructed model, the total areas for different types of suitability in the reserve were estimated (Table 2).

TABLE 2.

RATIO OF DIFFERENT CLASSES OF THE HABITAT SUITABILITY FOR THE RED FIELD IN THE CENTRAL FOREST

RESERVE

\begin{tabular}{|l|l|l|}
\hline $\begin{array}{l}\text { Class (probability of } \\
\text { suitability) }\end{array}$ & Area, ha & $\begin{array}{l}\text { Percentage, } \\
\%\end{array}$ \\
\hline$<0,4$ & 20677,2 & $88,3 \%$ \\
\hline $0,4-0,6$ & 1347,2 & $5,8 \%$ \\
\hline $0,6-0,8$ & 889,0 & $3,8 \%$ \\
\hline$>0,8$ & 488,8 & $2,1 \%$ \\
\hline
\end{tabular}

The total area of the most favorable habitats for the red vole is relatively small and amounts to about $6 \%$ of the Reserve's core territory. Same area is occupied by sites with an average degree of habitat suitable for the red vole.

\section{Conclusions}

Modern methods of statistical and GIS-analysis allow us to build multi-scale and high-quality models of spatial distribution of species. Built on the basis of the integral characteristics of the environment, the model is possible to determine the location and describe the size of most suitable areas for the habitat of the species. The results can be used to determine the ecological carrying capacity and to plan more detailed case population studies of of relict species in the Central Forest Biosphere Reserve.

In general, a similar identification of localized potential habitats of rare species may serve as a basis for developing measures for the biodiversity conservation and the creation of new protected areas.

\section{REFERENCES}

[1] A. P. Biatov, A. A. Ponomareva. Experience in modeling an ecological niche of a wild boar (Sus scrofa L.) on the territory of the "Slobozhansky" national natural park. Materials of the III scientific and methodological seminar "GIS and protected areas." Kharkov. "Printing House Madrid”. 2016, pp. 12 - 20.

[2] A.I.Tupikov, P.A. Ukrainskii. The comparative analysis of different approaches to the modeling of the species' areal in the maxent programme (by example of dione snake and steppe viper). Nauchnyye vedomosti. Natural Sciences. N 4 (225). Vol. 34. 2016, pp. 71-84.

[3] S.J. Phillips, R.P. Anderson, R.E. Schapire. Maximum entropy modeling of species geographic distributions. Ecol. Model. V. 190. 2006, pp. 231-259.

[4] R.J. Hijmans, L. Guarino, P. Mathur. DIVA-GIS Version 7.5 Manual. 2012. 71 pp. URL: http:// www.diva-gis.org/docs/ DIVA-GIS manual 7.pdf. [Accessed: Nov. 21, 2018].

[5] A.L. Stigall. Using ecological niche modelling to evaluate niche stability in deep time. J. Biogeography. V. 39. 2012, pp. 772-781.

[6] S.V. Dudov. Modeling of species distribution using topography and remote sensing data, with vascular plants of the Tukhuringra Range low mountain belt (Zeya Nature Reserve, Amur Region) as a case study. Zh. Obshch Biol. Mar-Apr; 77 (2). 2016, pp. 122-134.

[7] C. Murray-Smith, N.A. Brummitt, A.T. Oliveira-Filho, S. Bachman, J. Moat, E.M. Lughadha, E.J. Lucas. Plant diversity hotspots in the Atlantic coastal forests of Brazil. Conserv. Biol. V. 23. N 1. 2009, pp. $151-163$.

[8] J.C. Svenning, S. Normand, M. Kageyama. Glacial refugia of temperate trees in Europe: insights from species distribution modelling. J. Ecology. V. 96. № 6. 2008, pp. 1117-1127.

[9] A. M. Martell, W. A. Fuller. "Comparative demography of Clethrionomys rutilus in taiga and tundra in the low Arctic". Canadian Journal of Zoology 57 (11). 1979, pp. 2106-2120.

[10] E. V. Ivanter, Ye. A. Moiseyeva. By the Ecology of red vole (Clethrionomys rutilus Pall.). Transactions of KarRC RAS, N 1. 2015, pp. 37-47.

[11] A.V. Linzey, , H. Henttonen, , B. Sheftel, \& N. Batsaikhan. Myodes rutilus. The IUCN Red List of Threatened Species 2016. [Online]. Available e.T4975A115071234.http://dx.doi.org/10.2305/ IUCN.UK.2016-3.RLTS.T4975A22372469.en [Accessed: Jan. 29, 2019].

[12] A.V. Istomin. Small mammals in regional ecological monitoring (for example of Caspian-Baltic watershed). Pskov, 2008.

[13] Regional role of soils in the taiga ecosystems functioning Moscow. "Nauka", 2002.

[14] Factors of regulation of ecosystems in spruce forest. Leningrad. Nauka, 1983.

[15] A.V.Istomin, S.G. Mikhalap. Gradient approach and GISanalysis in the study of the spatial dynamics of the populations and communities of organisms. Bulletin of pskov state university. series: natural and physical-mathematical sciences Vol. 1. Pskov: PskovSU, 2012, pp. 49-55. 